\title{
Study on the value of antibiotic-resistant gene detection in Helicobacter pylori in China
}

\author{
JINFENG DAI, JING ZHAO, LIQI MAO, YUE HU and BIN LV
}

\author{
Department of Gastroenterology, The First Affiliated Hospital, \\ Zhejiang Chinese Medical University, Hangzhou, Zhejiang 310006, P.R. China
}

Received January 7, 2021; Accepted November 3, 2021

DOI: $10.3892 /$ etm.2022.11153

\begin{abstract}
The aim of the present study was to explore the value of detecting antibiotic-resistant genes in Helicobacter pylori (H. pylori) and the association between genotype and antibiotic resistance. Two gastric mucosa samples from each H. pylori-positive patient were collected. Each patient's $H$. pylori sample was cultured in vitro, and the agar plate dilution method was conducted. In addition, all patient samples were analyzed for the detection of antibiotic resistance-related mutant genes and VacA gene genotypes. The association between $\operatorname{VacA}$ genotypes and antibiotic resistance was also determined and the value of mutant gene detection in predicting $H$. pylori resistance to antibiotics was evaluated. In total, $133 \mathrm{H}$. pylori-positive patients were enrolled. A total of 22 strains of $H$. pylori failed to grow in in vitro culture and 25 strains were negative in a $H$. pylori gene test. Among 108 strains detected by PCR, a total of 39 VacA s1m1 strains, 69 VacA s1m2 strains and no VacA s2 strain were identified. There was no significant association between $V a c A$ genotypes and antibiotic resistance. The mutation rates of G616A in the $r d x A$ gene, T87A, G91A, A91G and G91T in the gyrA gene and $\mathrm{A} 2143 \mathrm{G}$ and $\mathrm{A} 2142 \mathrm{G}$ in the $23 \mathrm{~S}$ rRNA gene were 32.1, $32.3,22.6,12.9,6.5,81.8$ and $0.0 \%$, respectively. Among these mutant sites, the mutation coincidence rates were as follows, according to the agar plate dilution method: $r d x A$ G616A (81.8\%), gyrA G91T (66.7\%), gyrA G91A (54.5\%), 23 S rRNA A2143G (49.1\%), gyrA T87A (45.5\%), gyrA A91G (33.3\%), penicillin-binding protein $1(P B P 1)$ C556G (0.0\%), PBPI A562T (0.0\%), PBP1 A562G (0.0\%) and 16 S rRNA 926-927 (AT-GT) (0.0\%). VacA m subtypes were not associated with $H$. pylori antibiotic resistance. In conclusion, the present findings suggested that the detection of related mutant genes had a
\end{abstract}

Correspondence to: Professor Bin Lv, Department of Gastroenterology, The First Affiliated Hospital, Zhejiang Chinese Medical University, 54 Youdian Road, Shangcheng, Hangzhou, Zhejiang 310006, P.R. China

E-mail: lvbin@medmail.com.cn

Key words: Helicobacter pylori, antibiotic resistance, mutant gene, genotype, $\operatorname{VacA}$ clinical application value in predicting the antibiotic resistance of H.pylori, particularly resistance to clarithromycin and levofloxacin.

\section{Introduction}

Helicobacter pylori (H. pylori) is a spiral-shaped, microaerophilic and Gram-negative bacillus that was isolated by Marshall and Warrenin 1983 (1). H. pylori infection has been considered as an independent risk factor for gastric cancer for 27 years (2). Both laboratory and clinical studies have confirmed that H. pylori is a key factor in the occurrence of gastric cancer. The Kyoto consensus published in 2015 reported that $H$. pylori infection is an infectious disease. The earlier H.pylori is eradicated, the lower the incidence of gastric cancer will be. The eradication program should contain the most effective antibiotics available (3). It has been reported that eradication is more successful when antibiotics are selected based on individual susceptibility, community antibiotic sensitivity testing or antibiotic use and clinical prognosis data (3). However, the increased antibiotic resistance rates have become a severe challenge for the clinical eradication of $H$. pylori. The resistance rate to tetracycline (TET), amoxicillin (AMX) and furazolidone (FUR) in the majority of countries and regions in the world is relatively low $(<10 \%)$ (4-10). However, it has been reported that the abuse of antibiotics in Iran has led to a high antibiotic resistance rate of H. pylori to TET (38.5\%), AMX (27.1\%) and FUR (23.9\%) (11). As of June 2017, in all World Health Organization regions, the primary and secondary resistance rates of clarithromycin (CLA), metronidazole (MNZ) and levofloxacin (LEFX) were $\geq 15 \%$, except for the primary and secondary resistance rates of CLA in America (10\%; 95\% CI, 4-16\%) and Southeast Asia (10\%; 95\% CI, 5-16\%) and LEFX in Europe (11\%; 95\% CI, 9-13\%), while the global double resistance rate of CLA and MNZ was $19 \%$ (12). It is generally accepted that the main detection method of the antibiotic resistance of $H$. pylori is a drug sensitivity test based on the in vitro culture of $H$. pylori (13). Since $H$. pylori is a microaerophilic bacterium, its in vitro culture is challenging and time-consuming. In addition, numerous hospitals do not dispose the facilities and equipment to carry out this test. A previous study has indicated that there are several resistance mechanisms of $H$. pylori to antibiotics, including enhanced oxidative free radical scavenging activity, increased DNA repair enzyme activity, drug efflux pump expression and activation, 
as well as resistant gene expression, which is the focus of the present study (8). The Vaculationg cytotoxin gene $\mathrm{A}(\mathrm{VacA})$ gene exists in almost all $H$. pylori strains. However, only $\sim 50 \%$ of the strains can express $\mathrm{VacA}$, an important virulence factor in H. pylori production that causes vacuolation (13). The VacA gene is divided into middle region types $\mathrm{m} 1$ and $\mathrm{m} 2$, intermediate region i1, i2 and i3 and signal sequence types sla, s1b, s1c and s2 (14). The association between VacA subtypes and $H$. pylori resistance remains controversial $(15,16)$. The detection technology of drug-resistant genes is simpler and faster than the drug sensitivity in vitro culture-based test, and it can detect the H. pylori genotype at the same time (17). Therefore, the present study explored the value of antibiotic-resistant gene detection in H. pylori and the association between genotype and antibiotic resistance.

\section{Patients and methods}

Patients. Patients with $H$.pylori infection who were subjected to gastroscopy were enrolled between December 2017 and January 2020 in The First Affiliated Hospital of Zhejiang Chinese Medical University (Zhejiang, China). A total of $133 \mathrm{H}$. pylori-positive patients were enrolled in the present study, with a mean age of 45.1 years (age range, 18-71 years). The inclusion criteria were as follows: i) Age, 18-70 years old; ii) pathological findings of $H$.pylori infection; and iii) positive in ${ }^{[13 \mathrm{C}]}$-urea and ${ }^{[14 \mathrm{C}]}$-urea breath tests. The exclusion criteria were as follows: i) Gastroscopy contraindications; ii) diagnosis of severe cardiovascular diseases, immune disorders, poorly controlled diabetes, hypertension or recently planned subtotal gastrectomy; iii) inability to obtain biopsies due to poor coagulation function or anticoagulant drugs; iv) inability to complete gastroscopy due to lack of cooperation; and v) refusal to participate in a clinical trial.

The present study was approved by the Ethics Committee of The First Affiliated Hospital of Zhejiang Traditional Chinese Medical University (approval no. 2017-KL-054-02; Hangzhou, China). All patients provided written informed consent and general information, such as sex and age. Gastric mucosa samples were obtained from all patients (three samples per patient; each sample was $0.4-0.6 \mathrm{~mm}^{2}$ ). One sample was sent for routine pathological examination, one was cultured in vitro and subjected to a drug sensitivity test (agar plate dilution method), and one was sent for antibiotic resistance gene detection (PCR reverse dot blot; a chip with mutation sites presented in Table I). Finally, the sensitivity of $H$. pylori detection was compared between the two methods. The mutation sites tested in the present study were as follows: C556G, A562T and A562G in PBP1 for AMX; T87A, A91G, G91T and G91A in $g y r A$ for LEFX; 926-928 (AGA to TTC) and 926-927 (AG to GT) in 16S rRNA for TET; A2142G and A2143G in 23S rRNA for CLA; and G616A in $r d x A$ for MNZ (Table I). The mutation rate of the related gene sites was calculated in different antibiotic-resistant strains and the antibiotic resistance rate was calculated in gene mutant strains. Finally, the drug resistance rate was compared among different VacA genotypes.

H. pylori culture and drug sensitivity test

H. pylori culture. Gastric mucosa tissue immersed in Bacterial Preservation Fluid (Hangzhou ZhiYuan Medical Laboratory) was aspirated using a sterile pipette. A total of $0.5 \mathrm{ml}$ RIPA Lysis Buffer (Hangzhou ZhiYuan Medical Laboratory) was to form tissue homogenate. The tissue homogenate was then added to the culture medium of Columbia blood agar (500 g; Thermo Fisher Scientific Inc.). The medium was incubated in a microaerobic environment $\left(5 \% \mathrm{O}_{2} ; 10 \% \mathrm{CO}_{2} ; 85 \% \mathrm{~N}_{2}\right.$; $37^{\circ} \mathrm{C}$ ) for 2-3 days. The suspected colonies were selected for hematoxylin-eosin staining $(6.0 \%$ hematoxylin for $5 \mathrm{~min}$ and $0.5 \%$ eosin $2 \mathrm{~min}$ at room temperature) and were subjected to three enzyme identification tests [urease (Suzhou Haibo Biotechnology Co., Ltd., $37^{\circ} \mathrm{C}, 180 \mathrm{~min}$ ), oxidase (Beijing Luqiao Technology Co., Ltd., room temperature $5 \mathrm{~min}$ ) and catalase (Suzhou Haibo Biotechnology Co., Ltd. room temperature $5 \mathrm{~min}$; data not shown]. If the cultured bacteria were identified as $H$. pylori, the result was positive; otherwise, it was negative.

Drug sensitivity test of $H$. pylori. The H.pylori colonies were selected in sterile normal saline, shaken and mixed well. Next, the bacterial suspension containing 0.5 MCF (150 million bacteria/milliliter) was prepared. A total of $3 \mu \mathrm{l}$ bacterial suspension was collected using a pipette gun and added to the blood agar medium, with and without the following antibiotics: CLA (100 mg x 10 tablets; National Medical Products Administration), LEFX (100 mg x 10 capsules; China Academy of Food and Drug Control), MNZ (100 mg x 10 tablets; China Academy of Food and Drug control), AMX (0.25 g x 30 capsules; Dr. Ehrenstorfer GmbH). Three gas incubators were purchased from Thermo Fisher Scientific, Inc. (cat. no. 3427). The antibiotic concentration was the drug-sensitive minimum inhibitory concentration of the antibiotic: 1 clarithromycin, 2 levofloxacin, 2 amoxicillin, 2 furazolidone, 2 tetracycline and $8 \mu \mathrm{g} / \mathrm{ml}$ metronidazole. The medium was incubated in a microaerobic environment $\left(5 \% \mathrm{O}_{2} ; 10 \% \mathrm{CO}_{2} ; 85 \% \mathrm{~N}_{2} ; 37^{\circ} \mathrm{C}\right)$ for 2 days. The growth state of the strain was first observed in the culture medium without antibiotics. If it grew normally, the drug sensitivity test result could be interpreted; otherwise, the test needed to be repeated. Next, the colony growth state was observed in the culture medium containing antibiotics. If the colony growth was inhibited, $H$. pylor $i$ was considered to be sensitive to the antibiotic; otherwise, $H$. pylori was considered to be resistant to the antibiotic.

\section{$P C R$ reverse dot blot}

Preservation of samples and sample processing. Gastric mucosa samples were preserved at $-80^{\circ} \mathrm{C}$. For genotyping and drug resistance gene mutation testing of $H$. pylori, a nucleic acid extraction reagent was used [Nucleic acid extraction kit, Yaneng Biosciences (Shenzhen) Co., Ltd., cat. no. Yueshen Xiebei no. 20150098; model no. pathogen DNA (centrifugal column type); specification, 25 copies/box]. The concentration and purity of the template DNA prior to PCR was determined using a nucleic acid quantitative analyzer (Multi-mode Readers BioTek).

Preparation of amplification reaction solution. The sequences of the gene primers used are listed in Table II. The number of reaction solutions required for each test was $n+2$, where $\mathrm{n}=$ number of samples to be tested, and 2 equals one $H$. pylori positive quality control sample and one $H$. pylori negative 
Table I. A total of 12 gene mutation types associated with antibiotic resistance.

\begin{tabular}{|c|c|c|c|c|c|c|c|c|c|c|c|}
\hline \multirow{3}{*}{$\begin{array}{l}\text { Mutation } \\
\text { type } \\
\text { Gene } \\
\text { Mutant site }\end{array}$} & \multicolumn{3}{|c|}{ Amoxicillin } & \multicolumn{3}{|c|}{ Levofloxacin } & \multirow{2}{*}{\multicolumn{2}{|c|}{$\begin{array}{c}\text { Tetracycline } \\
16 S r R N A\end{array}$}} & \multirow{2}{*}{\multicolumn{2}{|c|}{$\frac{\text { Clarithromycin }}{23 S \mathrm{rRNA}}$}} & \multirow{3}{*}{$\begin{array}{c}\begin{array}{c}\text { Metron } \\
\text { idazole } \\
r d x A\end{array} \\
616\end{array}$} \\
\hline & & $P B P 1$ & & & gyrA & & & & & & \\
\hline & 556 & 562 & & 87 & 91 & & 926-928 & $926-927$ & 2142 & 2143 & \\
\hline Mutation & C556G & A562T & A562G & T87A & A91G G91T & G91A & AGA to TTC & AG to GT & A2142G & A2143G & G616A \\
\hline
\end{tabular}

Table II. Sequences of the forward primers.

\begin{tabular}{|c|c|c|}
\hline \multicolumn{3}{|l|}{ A, Wild-type } \\
\hline Primer (site) & Number & Sequence, $5^{\prime} \rightarrow 3^{\prime}$ \\
\hline 16S rRNA (926 928) & $16 \mathrm{~S} \mathrm{~W}$ & CGAAGATACACGAAGAAC \\
\hline 23S rRNA (2142/2143) & $23 \mathrm{~S} \mathrm{~W}$ & ACGGAAAGACCCCGTG \\
\hline $\operatorname{gyrA}(87)$ & $87 \mathrm{~W}$ & GGCGATAATGCGGTTT \\
\hline gyrA (91) & $91 \mathrm{~W}$ & TTTATGATGCACTAGTGAG \\
\hline PBP1 (556) & $556 \mathrm{~W}$ & AACCGGGACTTCCAATA \\
\hline PBP1 (562) & $562 W$ & AATGTGGATGCTTGGTTCA \\
\hline $\operatorname{rdxA}(565)$ & $565 \mathrm{~W}$ & ATTGGGTAAGAGGGTG \\
\hline $\operatorname{rdxA}(616)$ & $616 \mathrm{~W}$ & AAGTTGATGCAATTACTTG \\
\hline \multicolumn{3}{|l|}{ B, Mutant } \\
\hline Primer (site) & Number & Sequence, $5^{\prime} \rightarrow 3^{\prime}$ \\
\hline \multirow[t]{3}{*}{ 16S rRNA (926 928) } & 16S TTC & TCGATTCTACACGAAGAA \\
\hline & 16S GTA & ATTCGAGTATACACGAAG \\
\hline & 16S TGA & TCGATGATACACGAAGA \\
\hline \multirow[t]{2}{*}{ 23S rRNA (2142) } & A2142C & GACGGCAAGACCC \\
\hline & $\mathrm{A} 2142 \mathrm{G}$ & GACGGGAAGACCC \\
\hline 23S rRNA (2143) & A2143G & AGACGGAGAGACCCC \\
\hline $\operatorname{gyrA}(87)$ & $87 \mathrm{~K}$ & GCGATAARGCGGTTT \\
\hline \multirow[t]{3}{*}{ gyrA (91) } & $91 \mathrm{G}$ & ATGGTGCGYTAGTGAGA \\
\hline & $91 \mathrm{Y}$ & TTATTATGCGYTAGTGAG \\
\hline & $91 \mathrm{~N}$ & TTATAATGCGCTAGTGAG \\
\hline PBP1 (556) & $556 \mathrm{~S}$ & GTAAAAGCGGRACTTCT \\
\hline \multirow[t]{2}{*}{ PBP1 (562) } & $562 Y$ & AACAACTATATTGATGCTTG \\
\hline & $562 \mathrm{D}$ & АСТTСТАACAACGATATTG \\
\hline $\operatorname{rdxA}(565)$ & $565 \mathrm{~T}$ & GCTTTGTGTAAGAGGGT \\
\hline $\operatorname{rdxA}(616)$ & $616 \mathrm{~A}$ & CAAAAGTTGATACAATTACTT \\
\hline$\beta$-globin & IC & ССТСТТАТСТТССТСССАС \\
\hline
\end{tabular}

quality control material. Reaction solutions I, II and III were removed from the reagent box, melted and mixed. The amplification reaction solution was prepared according to the manufacturer's instructions. After the mixture was prepared, it was evenly mixed and centrifuged at $447.2 \mathrm{x}$ g for $10 \mathrm{sec}$ at $4^{\circ} \mathrm{C}$.

Sample addition. The sample DNA was tested (three times per sample; $4 \mu \mathrm{l}$ each) and added into three different amplification reaction solutions. Quality control samples (DNA of known dose) were also included (three times per sample; $4 \mu \mathrm{l}$ each) and added into three different amplification reaction solutions for PCR amplification.

PCR amplification. PCR was performed using the $H$. pylori Genotypes and drug resistance mutations detecting kit (PCR-reverse dot blot; Hangzhou Qianji Biosciences Co., Ltd. China). The PCR parameters are presented in Table III. The temperature rise and fall rate was $3.0^{\circ} \mathrm{C} / \mathrm{sec}$. 
Table III. Parameters for PCR amplification.

\begin{tabular}{llccc}
\hline Step no. & \multicolumn{1}{c}{ Step name } & Temperature, ${ }^{\circ} \mathrm{C}$ & Time & Cycle number \\
\hline 1 & Uracil-DNA glycosylase enzyme reaction & 50 & $10 \mathrm{~min}$ & 1 \\
2 & Initial denaturation & 95 & $10 \mathrm{~min}$ & 1 \\
3 & Denaturation & 95 & $30 \mathrm{sec}$ & 45 \\
4 & Annealing & 56 & $30 \mathrm{sec}$ & \\
5 & Extension & 72 & $30 \mathrm{sec}$ & \\
6 & Final extension & 72 & $5 \mathrm{~min}$ & 1 \\
\hline
\end{tabular}

Hybridization. Film strips marked with the sample number were placed in a plastic centrifuge tube $(15 \mathrm{ml})$, and $7 \mathrm{ml}$ liquid A was added. Next, three PCR products corresponding to the sample number were added, and the tube cover was tightened. Next, the centrifuge tube was heated in a boiling water bath for $10 \mathrm{~min}$. It was then removed, the cover was tightened, and the tube was placed into the hybridization instrument (Combi-H12 FINEPCR) at $48^{\circ} \mathrm{C}$ for $1.5 \mathrm{~h}$. A total of $45 \mathrm{ml}$ liquid $\mathrm{B}$ was added to a $50 \mathrm{ml}$ plastic centrifuge tube, which was then preheated at $48^{\circ} \mathrm{C}$ in the hybridization instrument.

Membrane washing. The membrane strips were removed and transferred to a $50 \mathrm{ml}$ tube containing preheated liquid $\mathrm{B}$, followed by gentle washing at $48^{\circ} \mathrm{C}$ for $15 \mathrm{~min}$.

Color rendering. The formula of the incubation solution was as follows: Solution A:Peroxidase $=2,000: 1$. The membrane was washed twice with liquid $\mathrm{A}$ at room temperature for 5 min each time. It was then washed with liquid $\mathrm{C}$ at room temperature for $1 \mathrm{~min}$, and the color developing solution was prepared. The membrane strip was then immersed in the color developing solution at room temperature for $10 \mathrm{~min}$ and rinsed with pure water twice to observe the results. Subsequently, mutation points turned blue (Fig. 1).

Statistical analysis. Fisher's exact test was used to compare two groups of classification data. The $\chi^{2}$ test was used for comparison of multiple sample rates. SPSS v17.0 (SPSS, Inc.) statistical software package was used for statistical analysis. $\mathrm{P}<0.05$ was considered to indicate a statistically significant difference.

\section{Results}

General patient information. The male:female ratio of the enrolled patients was 1.17:1 ( $\mathrm{P}>0.05)$. A total of 111 strains were successfully cultured in vitro, 109 strains were identified by pathologists (Fig. 2), while 108 strains were detected using PCR reverse dot blot. No significant difference in the sensitivity of $H$. pylori detection was identified between the three methods (agar plate dilution method, 83.5\%; PCR, 81.2\%; pathology, 82.0\%; $\mathrm{P}=0.89$ ). A total of 96 antibiotic-resistant strains were confirmed by both the agar plate dilution method and PCR reverse dot blot. According to genotyping, all strains were VacA-positive and type s1, including 44 cases that were type $\mathrm{s} 1 \mathrm{~m} 1$ and 69 that were type $\mathrm{s} 1 \mathrm{~m} 2$. The agar plate dilution method revealed that the resistance rate of MNZ was $90.1 \%$ (100/111), followed by $35.1 \%$ (39/111) for LEFX and $32.4 \%(36 / 111)$ for CLA. No strains were resistant to AMX, FUR and TET. A total of 34 strains were resistant to both CLA and MNZ, 37 strains were resistant to both LEFX and MNZ, and 23 strains were resistant to CLA, LEFX and MNZ.

Association analysis between mutations of different gene loci and drug resistance. The results of the agar plate dilution method and PCR reverse dot blot were not entirely consistent; $32.1 \%$ of strains that, according to the agar plate dilution method, were MNZ-resistant exhibited an $r d x A$ G616A mutation. In addition, numerous LEFX-related resistance gene sites were identified in gyrA. Among them, the T87A mutation accounted for 32.3\%, the G91A mutation for $22.6 \%$, the A91G mutation rate for $12.9 \%$ and the G91T mutation for $6.5 \%$. The main mutation in CLA-resistant strains was $23 S$ rRNA A2143G, accounting for $81.8 \%$, with the $23 S$ rRNA A2142G mutation accounting for $0.0 \%$. Neither AMX-resistant nor TET-resistant strains were identified in vitro (Table IV).

Among all the gene sites studied, $r d x A$ G616A had the highest accuracy in predicting $H$. pylori resistance (81.8\%), followed by gyrA G91T (66.7\%), gyrA G91A (54.5\%), 23 S rRNA A2143G (49.5\%), gyrA T87A (45.5\%), gyrA A91G (33.3\%) and 23S rRNA A2142G (0.0\%), while no drug resistance was identified in the strains with AMX-(PBP1 C556G, PBP1 A562T and PBP1 A562G) and TET-resistance-related gene mutations [926-927 (AG to GT) and 926-928 (AGA-TTC) in 16S rRNA], according to the in vitro drug sensitivity test (Table $\mathrm{V}$ ).

Among the genes, $81.8 \%$ of strains with a $r d x A$ mutation were revealed to be resistant to $\mathrm{MNZ}$, while $47.8 \%$ of strains with a gyrA mutation and $49.1 \%$ strains with a $23 S r R N A$ mutation were indicated to be resistant to LEFX and CLA, respectively (Table VI).

Drug resistance analysis of different VacA genotypes. All 108 patients with positive $H$. pylori genes presented the VacA s1 type; there were no VacA s2 type patients. Out of those, 39 (36.1\%) had VacA s1m1 strains and 69 (63.9\%) VacA s1m2 strains. As indicated using Fisher's exact test and $\chi^{2}$ analysis, there was no significant association between genotypes and overall drug resistance rate, multidrug resistance rate, CLA, LEFX or MNZ resistance rate $(\mathrm{P}>0.05$; Tables VII-XI). 

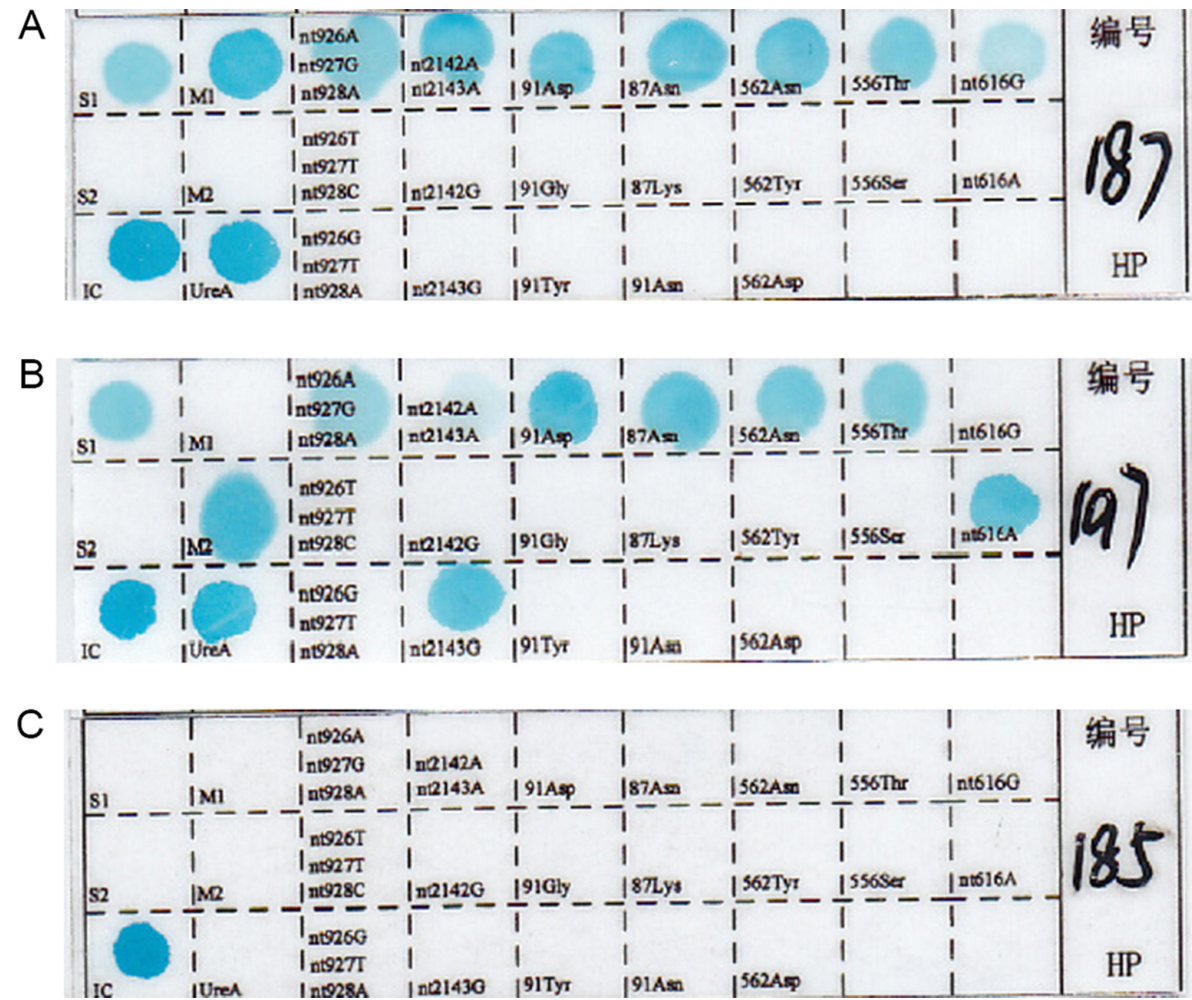

Figure 1. Membrane strips. (A) S1/M2/UreA/CagA; sensitive to all the antibiocs tested. (B) S1/M2/UreA/CagA; resistant to clarithromycin (23S rRNA A2143G) and metronidazole ( $r d x A$ G616A). (C) Helicobacter pylori negative.
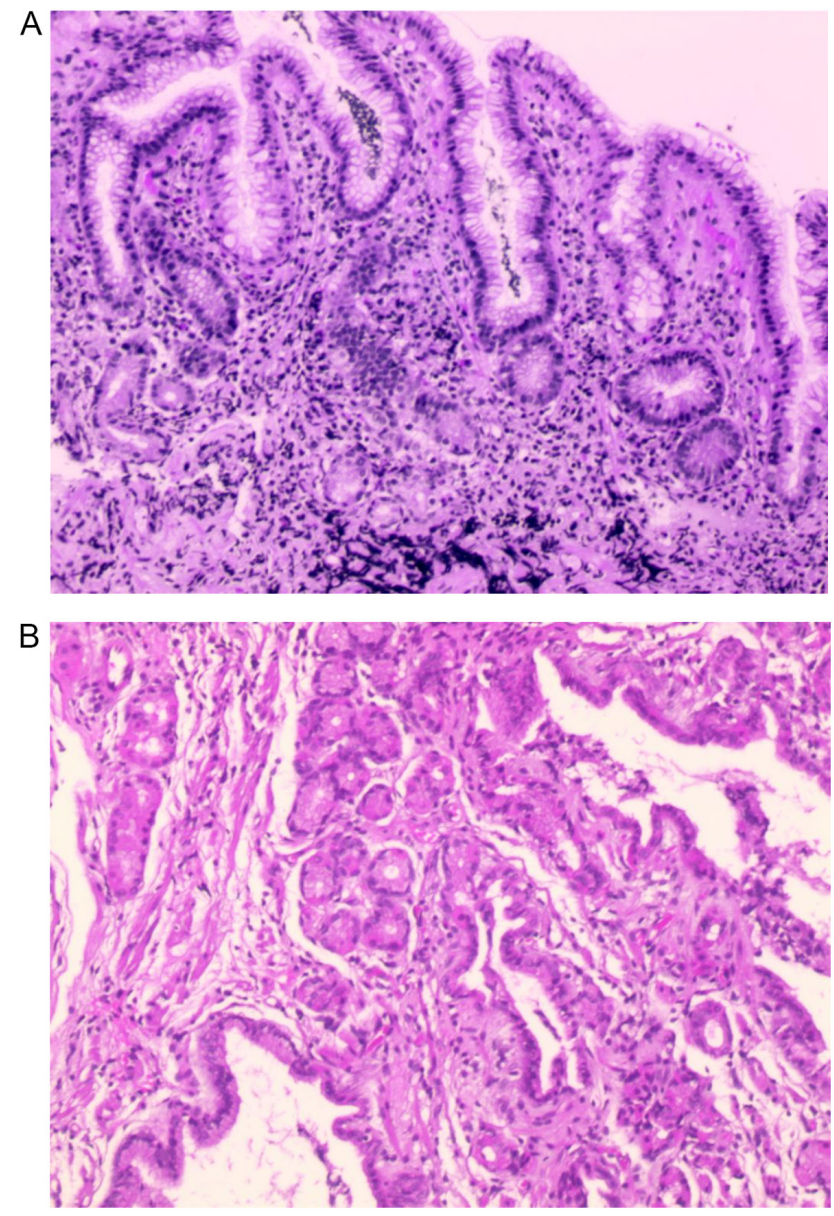

Figure 2. Pathological results. (A) Helicobacter pylori negative (magnification, x200). (B) Helicobacter pylori positive (magnification, x100)

\section{Discussion}

There are several mechanisms of $H$. pylori antibiotic resistance, and they vary among different antibiotics (8). The mechanism underlying CLA resistance involves reverse binding to the domain $\mathrm{V}$ of the $23 S$ rRNA gene in the ribosomal subunit $50 S$ in bacteria, thereby interfering with protein synthesis and promoting the early release of peptide tRNA from the recipient site, thus preventing the synthesis of the $H$. pylori peptide chain extension protein (18). Therefore, a mutation in domain $\mathrm{V}$ of the $23 S \mathrm{~S} R N A$ gene may decrease the affinity between the ribosome and drug, leading to the lack of binding between CLA and $50 S$ ribosome subunit. If the mutation cannot affect protein synthesis, $H$. pylori resistance occurs. In addition, if the mutation cannot entirely block the affinity between ribosome and antibiotics, sensitivity to antibiotics can still occur in vitro. Among the point mutations, certain are clinically more important than others. Seo et al (19) reported that 19.5, 0.9, 0.2 and $0.7 \%$ patients presented A2143G, A2142G, A2142C and both A2143G and A2142G mutations, respectively. The CLA-resistant group was treated with proton-pump inhibitor (PPI) twice a day, AMX $(1,000 \mathrm{mg})$ twice a day and MNZ $(500 \mathrm{mg})$ three times a day for 7 days (PAM). Groups with other mutations were treated with PPI twice a day, AMX $(1,000 \mathrm{mg})$ twice a day and CLA (500 mg) twice a day for 7 days (PAC). As revealed by ITT (Intention-To-Treat (ITT) and PP(Per-Protocol) analysis, there was a significant difference between the two groups [PAM vs. PAC, 55.4 vs. $74.3 \%, \mathrm{P}=0.001$ (ITT); 66.2 vs. $88.4 \%, \mathrm{P}=0.0001)(\mathrm{PP})]$ (16). Similarly, Ong et al (20) treated patients infected with $H$. pylori with 
Table IV. Proportion of gene mutations in drug-resistant heliobacter pylori strains shown by agar plate dilution.

\begin{tabular}{lcccc}
\hline Antibiotic & Resistant-strain number & Mutant sites & Mutant strain number & Mutant rate, $\%$ \\
\hline MNZ & 81 & G616A & 26 & 32.1 \\
LEFX & 31 & T87A & 10 & 32.3 \\
& & A91G & 4 & 12.9 \\
& & G91T & 2 & 6.5 \\
CLA & \multirow{2}{*}{33} & G91A & 7 & 22.6 \\
& & A2143G & 27 & 81.8 \\
AMX & \multirow{2}{*}{0} & A2142G & 0 & 0.0 \\
& & C556G & 0 & - \\
TET & \multirow{2}{*}{0} & A562T & 0 & - \\
& & A562G & 0 & - \\
\end{tabular}

MNZ, metronidazole; LEFX, levofloxacin; CLA, clarithromycin; AMX, amoxicillin; TET, tetracylin.

Table V. Proportion of resistant strains in vitro in strains with single gene loci mutation.

\begin{tabular}{lrrr}
\hline Mutant site & Mutant-strain number & Resistant-stain number & Resistance rate, $\%$ \\
\hline G616A & 33 & 27 & 81.8 \\
T87A & 22 & 10 & 45.5 \\
A91G & 12 & 4 & 33.3 \\
G91T & 3 & 2 & 66.7 \\
G91A & 11 & 6 & 54.5 \\
A2143G & 53 & 26 & 0 \\
A2142G & 1 & 0 & 0 \\
C556G & 10 & 0 & -1 \\
A562T & 1 & 0 & - \\
A562G & 0 & 0 & 0 \\
926 928 (AGA-TTC) & 0 & 0 & 0 \\
$926 \sim 927$ (AG-GT) & 0 & 0 & 0 \\
\hline
\end{tabular}

Table VI. Drug resistance ratio in different resistance gene mutant strains.

\begin{tabular}{lccc}
\hline Mutant gene & Mutant-strain number & Resistant-stain number & Positive rate, \% \\
\hline rdxA & 33 & 27 & 81.8 \\
gyrA & 46 & 22 & 47.8 \\
23 r $R$ NA & 53 & 26 & 49.1 \\
PBPI & 13 & 0 & 0 \\
l6S $r$ RNA & 0 & 0 & - \\
\hline
\end{tabular}

Table VII. Association between Vac A genotype and antibiotic resistance.

\begin{tabular}{lccc}
\hline Genotype & Resistant strains & Sensitive strains & Total \\
\hline s1m1 & 32 & 2 & 34 \\
s1m2 & 53 & 5 & 58 \\
Total & 85 & 7 & 92 \\
\hline
\end{tabular}

no CLA mutation points in $23 S$ rRNA with concomitant (1,000 mg AMX; $500 \mathrm{mg}$ CLA; $500 \mathrm{mg}$ MNZ and $30 \mathrm{mg}$ lansoprazole twice a day for 14 days) or tailored $(1,000 \mathrm{mg}$ AMX; $500 \mathrm{mg}$ CLA and $30 \mathrm{mg}$ lansoprazole twice a day for 14 days) therapy. There was no significant difference in the eradication rates between the groups in both point mutation-negative subjects ( 91.7 vs. $87.3 \%$; $\mathrm{P}=0.154$ ). These studies demonstrated that the detection of CLA mutation 
Table VIII. Association between Vac A genotype and multi-antibiotic resistance.

\begin{tabular}{lcccc}
\hline Genotype & $\begin{array}{c}\text { Single-antibiotic } \\
\text { resistant strains }\end{array}$ & $\begin{array}{c}\text { Double-antibiotic } \\
\text { resistant strains }\end{array}$ & $\begin{array}{c}\text { Triple-antibiotic } \\
\text { resistant strains }\end{array}$ & $\begin{array}{c}\text { Multi-antibiotic } \\
\text { resistant strains }{ }^{\text {b }}\end{array}$ \\
\hline s1m1 & 16 & 7 & 9 & 16 \\
s1m2 & 29 & 13 & 11 & 24 \\
Total & 45 & 20 & 20 & 40 \\
\hline
\end{tabular}

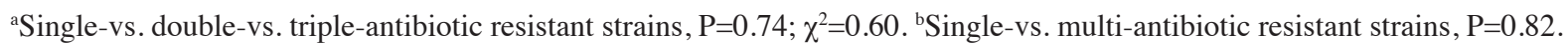

Table IX. Association between Vac $A$ genotype and CLA resistance.

\begin{tabular}{lccc}
\hline Genotype & $\begin{array}{c}\text { CLA-resistant } \\
\text { strains }\end{array}$ & $\begin{array}{c}\text { CLA-sensitive } \\
\text { strains }\end{array}$ & Total \\
\hline s1m1 & 14 & 20 & 34 \\
s 1m2 & 19 & 39 & 58 \\
total & 33 & 59 & 92
\end{tabular}

CLA, clarithromycin.

Table X. Association between Vac A genotype and MNZ resistance.

\begin{tabular}{lccc}
\hline Genotype & $\begin{array}{c}\text { MNZ-resistant } \\
\text { strains }\end{array}$ & $\begin{array}{c}\text { MNZ-sensitive } \\
\text { strains }\end{array}$ & Total \\
\hline s1m1 & 30 & 4 & 34 \\
s1m2 & 51 & 7 & 58 \\
total & 81 & 11 & 92 \\
\hline
\end{tabular}

MNZ, metronidazole.

Table XI. Association between Vac A genotype and LEFX resistance.

\begin{tabular}{lccc}
\hline Genotype & $\begin{array}{c}\text { LEFX-resistant } \\
\text { strains }\end{array}$ & $\begin{array}{c}\text { LEFX-sensitive } \\
\text { strains }\end{array}$ & Total \\
\hline s1m1 & 13 & 21 & 34 \\
s1m2 & 18 & 40 & 58 \\
total & 31 & 61 & 92 \\
\hline
\end{tabular}

LEFX, levofloxacin.

points in $23 S$ rRNA could be efficient for screening of CLA resistant strains in regions where the CLA resistance rate is $>15 \%$. In the present study, the CLA resistance rate was as high as $32.4 \%$, and the mutation rate of A2143G and A2142G in $23 \mathrm{~S} r R N A$ was 81.8 and $0 \%$ (Table IV), respectively. The sensitivity of A2142G and A2143G mutation in $23 \mathrm{~S} \mathrm{rRNA}$ was $81.8 \%$, rendering them ideal mutations for the detection of CLA resistance in $H$. pylori in China. Adding bismuth to standard triple therapy with CLA may eradicate $77.6 \%$ resistant strains with A2143G or A2142G mutation (21).

LEFX interferes with bacterial DNA synthesis by inhibiting DNA gyrase and topoisomerase IV (8). The gyrA gene encodes DNA gyrase, so its mutations can lead to the resistance of $H$. pylori to LEFX (22). Liou et al (23) used a modified sequential therapy containing LEFX and high-dose esomeprazole (40 mg esomeprazole and 1,000 mg AMX for the first 5 days, followed by $40 \mathrm{mg}$ esomeprazole, $250 \mathrm{mg}$ LEFX and $500 \mathrm{mg}$ MNZ for another 5 days; all administered twice daily) in patients who did not respond to first-line treatment. The eradication rates were $84.6 \%(11 / 13)$ and $95.1 \%(58 / 61)$ in patients with and without a $g y r A$ mutation, respectively $(\mathrm{P}=0.210)$, which indicated little value of gyrA mutation testing. However, Papastergiou et al (24) used a 7-day, genotypic resistance-guided triple $H$. pylori eradication therapy comprising esomeprazole, AMX and either CLA (wild-type $23 S$ rRNA), LEFX (23S rRNA mutated/wild-type gyrA) or rifabutin (mutated $23 S \mathrm{rRNA} / \mathrm{gyrA}$ ). The mutation sites of CLA in Papastergiou et al (24) were A2146G, A2146C and A2147G in the $23 S$ rRNA gene, while the mutation sites of LEFX were N87K, D91N, D91G and D91Y in the gyrA gene. For patients who received CLA-, LEFX- and rifabutin-containing triple therapy, the respective eradication rates were $24 / 27,20 / 20$ and $2 / 4$ by ITT and $24 / 24,19 / 19$ and $2 / 3$ by PP analysis. The overall eradication rates exhibited no significant difference between treatment-naïve and -experienced patients (ITT, 87.5 vs. $94.7 \%, \mathrm{P}=0.64$; $\mathrm{PP}, 96.4$ vs. $100 \%, \mathrm{P}=1.00$ ). Therefore, the unsatisfactory results of the previous trial may be linked to the high resistance rate of MNZ. The present results indicated that $74.2 \%$ of LEFX-resistant strains had gene mutations. The mutation rates of T87A, G91A, A91G and G91T in gyrA were $32.3,22.6,12.9$ and $6.5 \%$, respectively. The resistance rate of loci $91(36.1 \%)$ was similar to that in the study by Palmitessa et al (25). The coincidence rates of mutation sites, as determined by in vitro drug sensitivity test, were as follows: rdxA G616A (81.8\%), gyrA G91T (66.7\%), gyrA G91A (54.5\%), 23 S rRNA A2143G (49.5\%), gyrA T87A (45.5\%), gyrA A91G $(33.3 \%)$, and 23 S rRNA A2142G (0.0\%). Since the resistance rate of $g y r B$ is low (26), it was not detected in the present study, based on the economic benefit ratio. Meta analysis showed that second-line anti-H. pylori levofloxacin/amoxicillin-based triple (10-day regimen) therapy was significantly more effective than standard quadruple therapy [PPI+bismuth+two antibiotics; odds ratio, 5.05; 95\% CI, 2.74-9.31; $\mathrm{P}<0.001$; heterogeneity 
index $\left(\mathrm{I}^{2}\right)=75 \%$ ] (27). Simple molecular susceptibility testing for CLA and LEFX may achieve a high $H$. pylori eradication rate. If CLA or LEFX resistance does exist, administration of probiotic microorganisms along with triple therapy would be another treatment possibility (28).

In the present study, no case showed 926-928 and 926-927 loci mutations in $16 S$ rRNA, a TET-related resistance gene and 556 and 562 loci mutations in an AMX-related drug-resistant gene, $P B P 1$, occurred in 10 cases $(\mathrm{C} 556 \mathrm{G})$ and 3 case (A562T), respectively. However, TET- and AMX-resistant strains were not revealed to be among these mutant strains via the in vitro drug sensitivity test. At the same time, AMX-resistant strains detected in the in vitro drug sensitivity test identified no gene mutation. No FUR-resistant strains were cultured in the present study. In a review, Zamani et al (29) analyzed studies on the resistance of $H$. pylori to FUR published worldwide, suggesting that the resistance rate of $H$. pylori to FUR in most regions was $<5 \%$, which may be associated with A041G, A122G, C349A or G A78G, A112G, A335G, C156T and C165T mutations in the oorD gene and G353A, A356G, C357T, C347T, C347G and C346A mutations in the porD gene. The specificity and sensitivity of several mutation sites mentioned in the review by Zamani et al (29) requires further investigation, as they were not detected in the present study. Generally, the drug resistance rate of $H$. pylori to AMX, TET and FUR is low, and thus no drug resistance test is required prior to eradication if any of these three antibiotics are used (30) However, it should be noted that TET has been out of production for many years in China.

In a study by Lee et al (31), which enrolled $53 \mathrm{H}$. pyloripositive patients treated with MNZ-containing sequential or quadruple therapy between 2011 and 2015, $r d x A$ and $f r x A$ mutations in patients with $H$. pylori were analyzed via DNA sequencing. The results indicated that $r d x A$ mutations served a critical role in MNZ resistance and the outcomes of eradication therapy. Apart from $r d x A, f r x A$ and $\operatorname{fr} x B$ are among the most frequently studied mutations; however, previous studies have suggested that mutations in these two genes have a synergistic effect with $r d x A$ mutations in causing MNZ resistance, but cannot cause it alone (32-34). In theory, if the mutation rate of $r d x \mathrm{~A}$ in resistant strains is high enough, tailored therapy could achieve a high eradication rate of $H$. pylori, according to the $r d x A$ gene mutation detection results. However, only $32.1 \%$ of the MNZ-resistant strains had a $r d x A$ mutation in G616A in the present study, which was slightly higher than the rate observed in a study in Pakistan (32.1 vs. 23.5\%) (35). In addition, all strains (20/20) that were resistant to both CLA and LEFX were also resistant to MNZ in the present study. According to a study by Zhang et al (36), the $r d x A$ mutation was identified in $90.7 \%$ (49/54) of Chinese children. Therefore, $r d x A$ mutation detection in G616A may not be a good strategy to improve the eradication rate of $\mathrm{H}$. pylori among adults in high MNZ-resistant areas, while it may benefit Chinese children.

As aforementioned, $\mathrm{VacA}$ is an important virulence factor in $H$. pylori. The association between VacA subtypes and $H$.pylori resistance remains controversial. Karabiber et al (15) demonstrated that VacA s1c-positive H. pylori was more likely to lead to CLA resistance, while in MNZ-resistant strains $\operatorname{VacA}$ s1 and s1c were more likely to lead to resistance. Wang et al (37) reported that the resistance rate of MNZ in the VacA $\mathrm{s} 1 \mathrm{~m} 1 / \mathrm{m} 2$ strains was lower than that in the VacA s1m2 strain. However, Bachir et al (38) and Xu and Xie (39) demonstrated that the VacA genotype was not linked to $H$. pylori resistance. The present results indicated that there was no significant difference in $H$. pylori multidrug CLA, MNZ and LEFX resistance between VacA $\mathrm{m} 1$ and VacA $\mathrm{m} 2$ strains. The present results were consistent with studies by Bachir et al (38) and Xu and Xie (39). However, the s2 strain was not detected and the s1 subtype was not classified into s1a,slb and s1c in the current study. Intermediate region i1, i2 and i3 were not detected.

Antibiotic resistance is divided into primary and secondary resistance (40). The antibiotic resistance rate increases in association with the number of therapy failures (38). The majority of patients included in the present study has received treatment before; however, due to the unknown antibiotic history of the patient, it is not possible to accurately calculate the primary and secondary drug resistance rates of $H$. pylori in Zhejiang, China, thus further research is required. The average time required to culture $H$. pylori and perform an in vitro drug sensitivity test is 1 week. However, it only takes 1 day to detect drug-resistant genes, which can save valuable time. In addition, Giorgio et al (41) demonstrated that reverse transcription-quantitative PCR on feces, which is non-invasive compared with the use of gastric mucosa, can be a useful tool for the detection of DNA sequence and antibiotic resistance-related gene mutations in $H$. pylori. A previous study used gene chip technology to detect the drug resistance of $H$. pylori in children, and the main mutation sites were similar to those identified in the present study (17). Studies focused on adults have only been used for the detection of single antibiotic resistance $(42,43)$. The chip used in the present study covers five commonly used antibiotics. The results of gene detection were not identical to drug sensitivity test in vitro. At present, there is a lack of relevant clinical data to compare the accuracy of the two methods. However, a relevant clinical trial is in progress. There are numerous non-conventional rapid methods for antimicrobial resistance diagnostics, including whole genome sequencing (WGS), matrix-assisted laser desorption/ionization time-of-flight spectrometry, Fourier transform infrared spectroscopy and microfluidics technology. WGS is being expanded in China, while other methods require high purchase and maintenance costs and large space for equipment. Therefore, none of them can be widely carried out in the clinic (44).

In conclusion, $V a c A$ m subtypes were not linked to H.pylori antibiotic resistance. The detection of associated mutant genes C556G, A562T and A562G in PBP1 for AMX; T87A, A91G, G91T and G91A in $g y r A$ for LEFX; 926-928 (AGA to TTC) and 926-927 (AG to GT) in 16S rRNA for TET; A2142G and A2143G in 23S rRNA for CLA; and G616A in $r d x A$ for MNZ has a clinical application value in predicting the antibiotic resistance of $H$. pylori, particularly the resistance to CLA and LEFX.

\section{Acknowledgements}

Not applicable. 


\section{Funding}

The present study was supported by Zhejiang Natural Science Foundation Committee (grant no. Q20H030019), Zhejiang Administration of Traditional Chinese Medicine (grant no. 2017ZKL010) and Zhejiang Province Science and Technology Hall (grant no. 2016C37033).

\section{Availability of data and materials}

The datasets used and/or analyzed during the current study are available from the corresponding author on reasonable request.

\section{Authors' contributions}

BL designed the study. JZ analyzed and interpreted data. JD analyzed data and wrote the manuscript. YH and LM performed experiments and revised the manuscript. All authors read and approved the final manuscript. JD and JZ confirm the authenticity of all the raw data.

\section{Ethics approval and consent to participate}

The present study was approved by the Ethics Committee of The First Affiliated Hospital of Zhejiang Traditional Chinese Medical University (approval no. 2017-KL-054-02; Hangzhou, China). All patients provided written informed consent.

\section{Patient consent for publication}

Not applicable.

\section{Competing interests}

The authors declare that they have no competing interests.

\section{References}

1. Marshall BJ and Warren JR: Unidentified curved bacilli in the stomach of patients with gastritis and peptic ulceration. Lancet 1: 1311-1315, 1984.

2. Schistosomes, liver flukes and Helicobacter pylori. IARC Working Group on the evaluation of carcinogenic risks to humans. Lyon, 7-14 June 1994. IARC Monogr Eval Carcinog Risks Hum 61: 1-241, 1994

3. Sugano K, Tack J, Kuipers EJ, Graham DY, El-Omar EM, Miura S, Haruma K, Asaka M, Uemura N and Malfertheiner P, faculty members of Kyoto Global Consensus Conference: Kyoto global consensus report on Helicobacter pylori gastritis. Gut 64 $1353-1367,2015$

4. Cheng H, Hu F, Xie Y, Hu P, Wang J, Lv N, Zhang J, Zhang G, Zhou Z, Wu K, et al: Prevalence of Helicobacter pylori resistance to antibiotics and its influence on the treatment outcome in china: A mulficenter clinical study. Chin J Gastroenterol 12: 525-530, 2007

5. Song Z, Zhang J, He L, Chen M, Hou X, Li Z and Zhou L: Prospective multi-region study on primary antibiotic resistance of Helicobacter pylori strains isolated from Chinese patients. Dig Liver Dis 46: 1077-1081, 2014.

6. Sun QJ, Liang X, Zheng Q, Gu WQ, Liu WZ, Xiao SD and Lu H: Resistance of Helicobacter pylori to antibiotics from 2000 to 2009 in Shanghai. World J Gastroenterol 16: 5118-5121, 2010.

7. Liu DS, Wang YH, Zeng ZR, Zhang ZY, Lu H, Xu JM, Du YQ Li Y, Wang JB, Xu SP, et al: Primary antibiotic resistance of Helicobacter pylori in Chinese patients: A multiregion prospective 7-year study. Clin Microbiol Infect 24: 780.e5-780.e8, 2018.
8. Hu Y, Zhang M, Lu B and Dai J: Helicobacter pylori and antibiotic resistance, a continuing and intractable problem. Helicobacter 21: 349-363, 2016.

9. Shao Y, Lu R, Yang Y, Xu Q, Wang B and Ye G: Antibiotic resistance of Helicobacter pylori to 16 antibiotics in clinical patients. J Clin Lab Anal 32: e22339, 2018.

10. Khoury J, Geffen Y, Shaul R, Sholy H, Chowers Y and Saadi T: Secondary antibiotic resistance of Helicobacter pylori isolates in Israeli children and adults. J Glob Antimicrob Resist 10: 182-185, 2017.

11. Saniee P, Hosseini F, Kadkhodaei S, Siavoshi F and Khalili-Samani S: Helicobacter pylori multidrug resistance due to misuse of antibiotics in Iran. Arch Iran Med 21: 283-288, 2018.

12. Savoldi A, Carrara E, Graham DY, Conti M and Tacconelli E: Prevalence of antibiotic resistance in Helicobacter pylori: A systematic review and meta-analysis in world health organization regions. Gastroenterology 155: 1372-1382.e17, 2018.

13. Pohl D, Keller PM, Bordier V and Wagner K: Review of current diagnostic methods and advances in Helicobacter pylori diagnostics in the era of next generation sequencing. World $\mathrm{J}$ Gastroenterol 25: 4629-4660, 2019.

14. Thi Huyen Trang T, Thanh Binh T and Yamaoka Y: Relationship between vacA types and development of gastroduodenal diseases. Toxins (Basel) 8: 182, 2016.

15. Karabiber H, Selimoglu MA, Otlu B, Yildirim O and Ozer A: Virulence factors and antibiotic resistance in children with Helicobacter pylori gastritis. J Pediatr Gastroenterol Nutr 58: 608-612, 2014.

16. Liou JM, Chang CY, Chen MJ L, et al: The Primary Resistance of Helicobacter pyloriin Taiwan after the National Policy to Restrict Antibiotic Consumption and Its Relation to Virulence Factors-A Nationwide Study. PLoS One 10: 5, e0124199, 2015.

17. Yin G, Bie S, Gu H, Shu X, Zheng W, Peng K, Zhao H, Li F, Chen B, Botchway BOA, et al: Application of gene chip technology in the diagnostic and drug resistance detection of Helicobacter pylori in children. J Gastroenterol Hepatol 35: 1331-1339, 2020.

18. Brisson-Noël A, Trieu-Cuot P and Courvalin P: Mechanism of action of spiramycin and other macrolides. J Antimicrob Chemother 22 (Suppl B): S13-S23, 1988.

19. Seo SI, Do BJ, Kang JG, Kim HS, Jang MK, Kim HY and Shin WG: Helicobacter pylori eradication according to sequencing-based $23 \mathrm{~S}$ ribosomal RNA point mutation associated with clarithromycin resistance. J Clin Med 9: 54, 2019.

20. Ong S, Kim SE, Kim JH, Yi NH, Kim TY, Jung K, Park MI and Jung HY: Helicobacter pylori eradication rates with concomitant and tailored therapy based on 23S rRNA point mutation: A multicenter randomized controlled trial. Helicobacter 24: e12654, 2019.

21. Kim YJ, Chung WC and Kim DB: Efficacy of bismuth added to standard triple therapy as the first-line eradication regimen for Helicobacter pylori infection. Helicobacter 26: e12792, 2021.

22. Hooper DC: Emerging mechanisms of fluoroquinolone resistance. Emerg Infect Dis 7: 337-341, 2001.

23. Liou JM, Chen CC, Chen MJ, Chang CY, Fang YJ, Lee JY, Sheng WH, Wang HP, Wu MS and Lin JT: Empirical modified sequential therapy containing levofloxacin and high-dose esomeprazole in second-line therapy for Helicobacter pylori infection: A multicentre clinical trial. J Antimicrob Chemother 66: 1847-1852, 2011.

24. Papastergiou V, Mathou N, Licousi S, Evgenidi A, Paraskeva KD, Giannakopoulos A, Stavrou PZ, Platsouka E and Karagiannis JA: Seven-day genotypic resistance-guided triple Helicobacter pylori eradication therapy can be highly effective. Ann Gastroenterol 31: 198-204, 2018.

25. Palmitessa V, Monno R, Panarese A, Cuppone R, Burattini O, Marangi S, Curlo M, Fumarola L, Petrosillo A, Parisi A, et al: Evaluation of antibiotic resistance of Helicobacter pylori strains isolated in Bari, Southern Italy, in 2017-2018 by phenotypic and genotyping methods. Microb Drug Resist 26: 909-917, 2020

26. Miyachi H, Miki I, Aoyama N, Shirasaka D, Matsumoto Y, Toyoda M, Mitani T, Morita Y, Tamura T, Kinoshita S, et al: Primary levofloxacin resistance and gyrA/B mutations among Helicobacter pylori in Japan. Helicobacter 11: 243-249, 2006.

27. Di Caro S, Fini L, Daoud Y, Grizzi F, Gasbarrini A, De Lorenzo A, Di Renzo L, McCartney S and Bloom S: Levofloxacin/amoxicillin-based schemes vs quadruple therapy for Helicobacter pylori eradication in second-line. World J Gastroenterol 18: 5669-5678, 2012. 
28. Debnath $\mathrm{N}$ and Yadav A: Indigenous probiotic lactobacillus strains to combat gastric pathogen Helicobacter pylori: Microbial interference therapy. Indu pal Kaur, Sandip V. Pawar and Praveen rishi. Chandigarh, India. In: Probiotic Research in Therapeutics, pp215-230, 2021.

29. Zamani M, Rahbar A and Shokri-Shirvani J: Resistance of Helicobacter pylori to furazolidone and levofloxacin: A viewpoint. World J Gastroenterol 23: 6920-6922, 2017.

30. Xie C and Lv N: Helicobacter pylori infection in China. Dis Surveill 33: 272-275, 2018.

31. Lee SM, Kim N, Kwon YH, Nam RH, Kim JM, Park JY, Lee YS and Lee DH: rdxA, frxA, and efflux pump in metronidazole-resistant Helicobacter pylori: Their relation to clinical outcomes. J Gastroenterol Hepatol 33: 681-688, 2018.

32. Jeong JY, Mukhopadhyay AK, Dailidiene D, Wang Y, Velapatiño B, Gilman RH, Parkinson AJ, Nair GB, Wong BC, Lam SK, et al: Sequential inactivation of rdxA (HP0954) and frxA (HP0642) nitroreductase genes causes moderate and high-level metronidazole resistance in Helicobacter pylori. J Bacteriol 182: 5082-5090, 2000.

33. Jeong JY and Berg DE: Mouse-colonizing Helicobacter pylori SS1 is unusually susceptible to metronidazole due to two complementary reductase activities. Antimicrob Agents Chemother 44: 3127-3132, 2000

34. Kwon DH, El-Zaatari FA, Kato M, Osato MS, Reddy R, Yamaoka Y and Graham DY: Analysis of $\mathrm{rdxA}$ and involvement of additional genes encoding $\mathrm{NAD}(\mathrm{P}) \mathrm{H}$ flavin oxidoreductase (FrxA) and ferredoxin-like protein $(\mathrm{FdxB})$ in metronidazole Helicobacter pylori. Antimicrob Agents Chemother 44: 2133-2142, 2000

35. Rasheed F, Campbell BJ, Alfizah H, Varro A, Zahra R, Yamaoka Y and Pritchard DM: Analysis of Clinical Isolates of Helicobacter pylori in Pakistan reveals high degrees of pathogenicity and high frequencies of antibiotic resistance. Helicobacter 19: 387-399, 2014.

36. Zhang Y, Wen Y, Xiao Q, Zheng W, Long G, Chen B, Shu X and Jiang M: Mutations in the antibiotic target genes related to clarithromycin, metronidazole and levofloxacin resistance in Helicobacter pylori strains from children in China. Infect Drug Resist 13: 311-322, 2020.
37. Wang D, Guo Q, Yuan Y and Gong Y: The antibiotic resistance of Helicobacter pylori to five antibiotics and influencing factors in an area of China with a high risk of gastric cancer. BMC Microbiol 19: 152, 2019

38. Bachir M, Allem R, Tifrit A, Medjekane M, Drici AE, Diaf M and Douidi KT: Primary antibiotic resistance and its relationship with cagA and vacA genes in Helicobacter pylori isolates from Algerian patients. Braz J Microbiol 49: 544-551, 2018.

39. Xu J and Xie GY: Relationship between cagA and VacA genotypes of Helicobacter pylori and drug resistance. Med J West China 5: 818-819, 821, 2010 (In Chinese).

40. Schubert JP, Gehlert J, Rayner CK, Roberts-Thomson IC, Costello S, Mangoni AA and Bryant RV: Antibiotic resistance of Helicobacter pylori in Australia and New Zealand: A systematic review and meta-analysis. J Gastroenterol Hepatol 36: 1450-1456, 2021.

41. Giorgio F, Ierardi E, Sorrentino C, Principi M, Barone M, Losurdo G, Iannone A, Giangaspero A, Monno R and Di Leo A: Helicobacter pylori DNA isolation in the stool: An essential pre-requisite for bacterial noninvasive molecular analysis. Scand J Gastroenterol 15: 1429-1432, 2016.

42. Chen S, Li Y and Yu C: Oligonucleotide microarray: A new rapid method for screening the 23S rRNA gene of Helicobacter pylori for single nucleotide polymorphisms associated with clarithromycin resistance. J Gastroenterol Hepatol 23: 126-131, 2008.

43. Xuan SH, Zhou YG, Shao B, Cui YL, Li J, Yin HB, Song XP Cong H, Jing FX, Jin QH, et al: Enzymic colorimetry-based DNA chip: A rapid and accurate assay for detecting mutations for clarithromycin resistance in the 23S rRNA gene of Helicobacter pylori. J Med Microbiol 58: 1443-1448, 2009.

44. Kaprou GD, Bergšpica I, Alexa EA, Alvarez-Ordóñez A and Prieto M: Rapid methods for antimicrobial resistance diagnostics. Antibiotics (Basel) 10: 209-239, 2021.

(i) $(5)$ This work is licensed under a Creative Commons Attribution-NonCommercial-NoDerivatives 4.0 International (CC BY-NC-ND 4.0) License. 